\title{
Digital Badges in Education: Trends, Issues, and Cases
}

\author{
Li Zhou ${ }^{1,2}$, Liwen Chen ${ }^{*}$
}

${ }^{1}$ Huaiyin Institute of Technology, Huaian, CHINA

2 Ph.D. Program of Technology Management, Chung-Hua University, Hsinchu, TAIWAN

${ }^{3}$ Graduate Institute of Technology Management, Chung-Hua University, Hsinchu, TAIWAN

Received 18 March 2018 - Revised 19 April 2018 • Accepted 21 April 2018

Lin Y. Muilenburg and Zane L. Berge (Eds.). Digital Badges in Education: Trends, Issues, and Cases. New York: Routledge, 2016. 288 pp. ISBN-13: 978-1138857599. US\$50.30 (pbk).

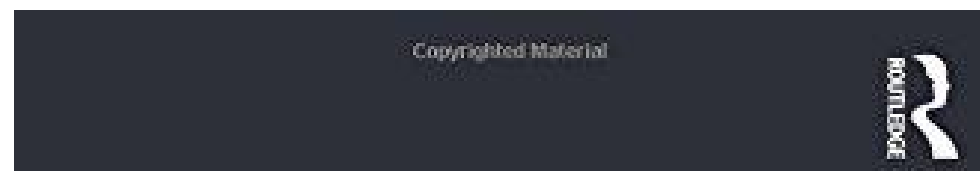

\section{DIGITAL BADGES IN EDUCATION} Trends, Issues, and Cases

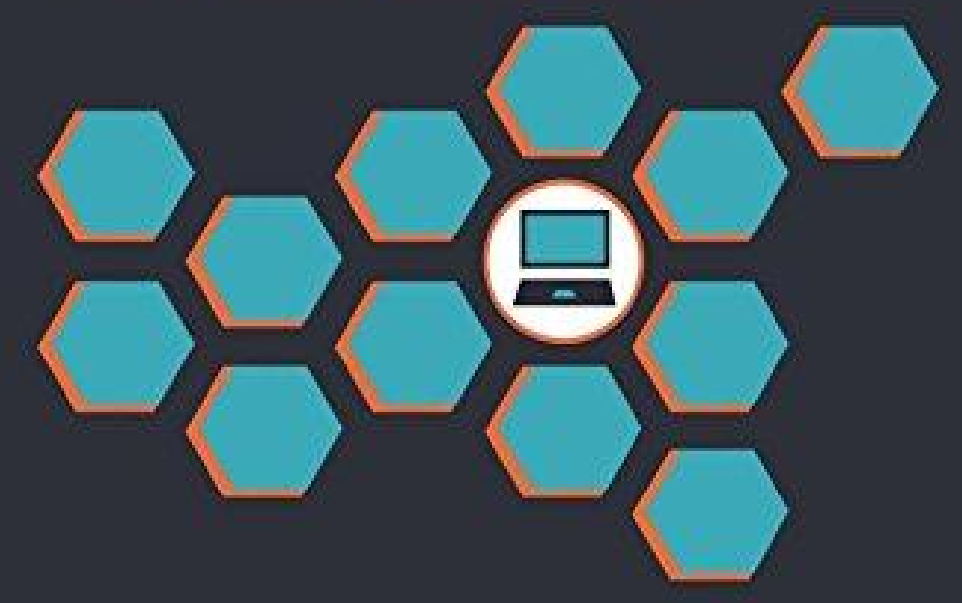

Edited by Lin Y. Muilenburg and Zane L. Berge 
Digital badges may be alternative credentials to document and certify individuals' competency more flexibly, thereby linking the worlds of education, work and community in a meaningful way. Digital badges are designed to accurately reflect the achievements of contemporary learners and they are currently influencing educational practices. This timely book attempts to tackle this question for K12 learners, higher education courses, adult learning researchers, and people in the business.

The book's 288 pages are tightly structured around digital badges in education in twenty-five chapters, divided into two sections: Part I Trends and Issues and Part II Cases in education. The text is focused on digital badges as online-based visual representations that utilize ample metadata to signify learners' certain credentials and achievements in varied subjects. Learning design, assessment, specific cases in both academic and professional settings, and the necessary components, functions and value are explored, together with the specific problems learners face.

The authors pay attention to the history of digital badges, design philosophy, positive trends and the advantages of a badging system. Moreover, they describe the motivational function and categories of digital badges in both formal and informal education, especially higher educational settings. The real strength of this book lies in the authors' success in providing a series of abundant cases studies and building a rigorous theoretical framework for a digital badging system. Since some of the case studies may refer to different settings, readers should bear the authors' perspectives in mind and are urged to maintain those perspectives through the underlying values ascribed within each chapter.

The book begins with the history and context of open digital badges in education the badge-friendly policies, and the authors give their opinion of unbundling education and the goals of badges. Then, they analyze the consistency of open digital badges ecosystem models and cases in chapters 2 and 3 to help readers to understand ecosystem factors, rigorous assessments and credentialing systems. The link between well-defined CompetencyBased Education and a robust digital badging system as a contemporary means to indicate the achievement of specific competencies in higher education is demonstrated in the next chapter. The motivational function of digital badges is explained in chapters 5 to 6 with an outline of the theoretical foundation of the design and motivation of badges. The authors explain the connection between badges and learners' motivation based on the goal achievement theory and the expectancy-value theory.

Chapters 7 and 8 contain a description of methodological design techniques and considerations with worthwhile suggestions for educational design, especially in terms of distribution frequency and time. The achievements and skill trees used in popular video games are discussed in Chapter 7, while instructional design principles from practice and experience are shared in Chapter 8 in order to provide guidelines for digital badge designs from a single badge to a "badge family".

In chapters 9 and 10, the authors demonstrate the positive trends and advantages of badge systems in both formal and informal education settings, especially in higher education. They explain the effect of a badge in practice, and explore how badges may intersect and begin to merge with other trends in education, specifically learning at scale and big data. Chapter 11 helps to understand the value, major purposes, and value priorities of badges with three main groups of different stakeholders: badge earners, issuers and badge consumers.

Chapters 12 to 15 contain cases of digital badges for K-12 learners with the aim of supporting them through college and making them ready for a career, from formal education to an informal learning environment. Empirical case studies adopted in higher education are provided in Chapters 16 to 20, including healthcare-related badges, transdisciplinary competency-based programs, a comparative analysis of customized badges and the use of modular design frameworks of badges, and badges in composition courses. The last five chapters contain cases of adult learning related to teachers' learning journey in terms of digital badge systems, the evolution of global-ready teacher badging, digital badges as a motivator in MOOCs, learning technologies badges in a teaching-related pilot phase, and continuing education in non-credit, just-in-time, short courses with a company.

The highlight of the book is a description of the digital badge instructional design considerations, which include an assessment, processes, various examples of badges and technical design considerations. Also, instructional design considerations, which include an assessment model, rewarding students who show growth in achievement, other achievement categories such as demonstrating academic behavior and performing community service, badges issued in pathways to further promote student motivation. The authors propose several key principles to improve the precision of badge movement: rigorous assessment processes, the disruptive power of badges as legitimate credentials, gamification, and collaboration among badge providers. Moreover, the book is particularly rich in examples of digital badges in both formal and informal learning.

However, the shortcomings of the book focus on its research method, which consists of almost all case studies, although the cases are spread across main state universities. Additionally, open digital badges are described in the first three chapters, but these are renamed 'digital badges' in the remainder of the book without describing how digital badges work. Moreover, the motivation levels of males and females were different based on the survey in 
Chapter 12, but the strategic patterns of different genders are not explained, which may be of interest in the future. Besides, it may have better enabled readers to list the badge platforms used in the book.

The book consists of an organized review of the main digital badge themes in education, with each chapter outlining the main thinking based on the current project practices. Most authors are educational specialists, education technology providers and designers in companies, who have more experience in educational practices and the field of badge design. The aim of this book is to ask the right questions about the use of digital badges in education and, as such, it succeeds in being authoritative and friendly. Its contents are helpful and meaningful for educators to research the emerging field of digital badges.

\section{ACKNOWLEDGEMENT}

This work was supported in part by the Higher Education and Teaching Research under Grant Number (2017XGJ17) at the Huaiyin Institute of Technology. This research was also funded by the Ministry of Science and Technology under Grant Number MOST 103-2511-S-216-002.

\section{http://www.ejmste.com}

